\title{
Plasmodium falciparum susceptibility to standard and potential anti-malarial drugs in Dakar, Senegal, during the 2013-2014 malaria season
}

Bécaye Fall ${ }^{1}$, Cheikhou Camara ${ }^{2}$, Mansour Fall ${ }^{3}$, Aminata Nakoulima ${ }^{4}$, Pierre Dionne $^{5}$, Bakary Diatta ${ }^{3}$, Yaya Diemé 1 , Boubacar Wade ${ }^{6}$ and Bruno Pradines ${ }^{1,7,8,99^{*}}$

\begin{abstract}
Background: In 2006, the Senegalese National Malaria Control Programme recommended artemisinin-based combination therapy (ACT) as the first-line treatment for uncomplicated malaria. Since the introduction of ACT, there have been very few reports on the level of Plasmodium falciparum resistance to anti-malarial drugs. An ex vivo susceptibility study was conducted on local isolates obtained from the Hôpital Principal de Dakar (Dakar, Senegal) from November 2013 to January 2014.

Methods: Eighteen P. falciparum isolates were sussessfully assessed for ex vivo susceptibility to chloroquine (CQ), quinine $(\mathrm{QN})$, monodesethylamodiaquine $(\mathrm{MDAQ})$, the active metabolite of amodiaquine, mefloquine $(\mathrm{MQ})$, lumefantrine (LMF), artesunate (AS), dihydroartemisinin (DHA), the active metabolite of artemisinin derivatives, pyronaridine (PND), piperaquine (PPQ), and, Proveblue (PVB), a methylene blue preparation, using the HRP2-based ELISA test.

Results: The prevalence of isolates with reduced susceptibility was $55.6 \%$ for $\mathrm{MQ}, 50 \%$ for $\mathrm{CQ}, 5.6 \%$ for QN and MDAQ, and $0 \%$ for DHA, AS and LMF. The mean $I_{50}$ for PND, PPQ and PVB were $5.8 \mathrm{nM}, 32.2 \mathrm{nM}$ and $5.3 \mathrm{nM}$, respectively.

Conclusions: The prevalence of isolates with a reduced susceptibility to MQ remains high and stable in Dakar. Since 2004, the prevalence of CQ resistance decreased, but rebounded in 2013 in Dakar. PND, PPQ and PVB showed high in vitro activity in P. falciparum parasites from Dakar.
\end{abstract}

Keywords: Malaria, Plasmodium falciparum, Anti-malarial, In vitro, Resistance, Senegal, Proveblue, Methylene blue

\section{Background}

In response to increasing chloroquine resistance, Senegal switched in 2004 to sulphadoxine-pyrimethamine with amodiaquine as the first-line therapy for malaria. In 2006, the Senegalese National Malaria Control Programme recommended artemisinin-based combination therapy (ACT) as the first-line treatment for uncomplicated malaria. The combined sulphadoxine-pyrimethamine and amodiaquine treatment was changed to artemether-lumefantrine or

\footnotetext{
* Correspondence: bruno.pradines@free.fr

'Laboratoire d'étude de la chimiosensibilité du paludisme, Fédération des laboratoires, Hôpital Principal de Dakar, Dakar, Sénégal

7Unité de Parasitologie et d'Entomologie, Département des Maladies Infectieuses, Institut de Recherche Biomédicale des Armées, Brétigny sur Orge, France

Full list of author information is available at the end of the article
}

artesunate-amodiaquine. Since 2006, more than 1.5 million ACT-based treatments have been administered in Senegal [1]. In 2006, the Senegalese National Malaria Control Programme also recommended testing all suspected cases of malaria with the Plasmodium falciparum histidine-rich protein 2 (PfHRP2)-based rapid diagnostic test (RDT). Since this time, ACT use has been restricted to confirmed malaria cases to reduce drug resistance. In 2009, 184,170 doses of ACT were dispensed at public health facilities in Senegal [2].

Since the introduction of ACT, there have been very few reports on the level of $P$. falciparum resistance to anti-malarial drugs. The last ex vivo susceptibility study was conducted in 2010 in Dakar (Médina district) [3] and in 2011 in Thies [4]. To determine whether parasite 
susceptibility has been affected by the new anti-malarial policies, an ex vivo susceptibility study was conducted on local isolates from Dakar obtained from the Hôpital Principal de Dakar between November 2013 and January 2014. The malaria isolates were assessed for susceptibility to standard drugs such as chloroquine (CQ), quinine $(\mathrm{QN})$, monodesethylamodiaquine (MDAQ), the active metabolite of amodiaquine, mefloquine (MQ), lumefantrine (LMF), artesunate (AS), dihydroartemisinin (DHA), the active metabolite of artemisinin derivatives, and new anti-malarial drugs, such as pyronaridine (PND), piperaquine (PPQ) and Proveblue (PVB), a methylene blue preparation that complies with the European Pharmacopoeia and contains limited organic impurities and heavy metals of recognised toxicity.

\section{Methods}

\section{Plasmodium falciparum isolates}

In total, 24 patients (seven females and 17 males) with malaria were recruited from 19 November 2013 to 7 January 2014 at the Hôpital Principal de Dakar. Venous blood samples were collected in Vacutainer ${ }^{\circ}$ ACD tubes (Becton Dickinson, Rutherford, NJ, USA) prior to patient treatment. Parasitaemia ranged from 0.001 to $0.33 \%$ in the male group and from 0.001 to $3.3 \%$ in the female group. Of the 24 patients, $67 \%$ were recruited from the emergency department and the remainder were recruited from the intensive care unit (21\%), paediatric department (8\%) and maternity department (4\%). Informed verbal consent was obtained from patients and/or their parents before blood collection. Assessments of $P$. falciparum susceptibility to anti-malarial drugs were performed with the same venous blood sample used for diagnostic purposes. The study was reviewed and approved by the ethical committee of the Hôpital Principal de Dakar. Patients were successfully treated by QN.

Thin blood smears were stained using a $\mathrm{RAL}^{\circ}$ kit (Réactifs RAL, Paris, France) based on eosin and methylene blue and were examined to determine $P$. falciparum density and to confirm monoinfection. Parasitized erythrocytes were washed three times in RPMI 1640 medium (Invitrogen, Paisley, UK) buffered with 25 mM HEPES and $25 \mathrm{mM} \mathrm{NaHCO}_{3}$. If parasitaemia exceeded $0.5 \%$, infected erythrocytes were diluted to $0.5 \%$ with uninfected erythrocytes (human blood type $\mathrm{A}+$ ) and resuspended in RPMI 1640 medium supplemented with 10\% human serum (Abcys S.A. Paris, France), for a final haematocrit of $1.5 \%$.

\section{Drugs}

CQ, QN and DHA were purchased from Sigma (Saint Louis, MO, USA). MDAQ was obtained from the World Health Organization (Geneva, Switzerland), MQ was purchased from Roche (Paris, France), and LMF was purchased from Novartis Pharma (Basel, Switzerland). AS, PPQ and PND were obtained from Shin Poong Pharm Co (Seoul, Korea) and PVB from Provepharm SAS (Marseille, France). QN, MDAQ, MQ, DHA, AS, and PPQ were first dissolved in methanol and then diluted in water to final concentrations ranging from 6 $\mathrm{nM}$ to $3,149 \mathrm{nM}$ for $\mathrm{QN}, 1.9$ to $1,988 \mathrm{nM}$ for MDAQ, 1.5 to $392 \mathrm{nM}$ for MQ, 0.1 to $107 \mathrm{nM}$ for DHA, 0.1 to $98 \mathrm{nM}$ for AS and 1.9 to $998 \mathrm{nM}$ for PPQ. CQ, PND and PVB were resuspended and diluted in water to final concentrations ranging from $6 \mathrm{nM}$ to $3,231 \mathrm{nM}, 0.4$ to $199 \mathrm{nM}$ and 0.5 to $500 \mathrm{nM}$, respectively. LMF was resuspended and diluted in ethanol to obtain final concentrations ranging from $0.6 \mathrm{nM}$ to $310 \mathrm{nM}$.

The batches of plates were tested and validated on the CQ-susceptible 3D7 strain (West-Africa) and the CQresistant W2 strain (Indochina) (MR4, Virginia, USA) in three to six independent experiments using the same conditions described in the paragraph below. The two strains were synchronized twice with sorbitol before use [5], and clonality was verified every 15 days using PCR genotyping of the polymorphic genetic markers msp1 and $m s p 2$ and microsatellite loci [6,7] and annually by an independent laboratory from the Worldwide Antimalarial Resistance Network (WWARN).

\section{Ex vivo assay}

For the in vitro isotopic microtests, $100 \mu \mathrm{l}$ of synchronous parasitized red blood cells (final parasitaemia, $0.5 \%$; final haematocrit, 1.5\%) was aliquoted into 96-well plates pre-dosed with anti-malarial drugs. The plates were incubated in a sealed bag for $72 \mathrm{hrs}$ at $37^{\circ} \mathrm{C}$ with the atmospheric generators for capnophilic bacteria, Genbag $\mathrm{CO}^{\circ}$ at $5 \% \mathrm{CO}_{2}$ and $15 \% \mathrm{O}_{2}$ (BioMérieux, Marcy l'Etoile, France) [8]. After thawing the plates, haemolysed cultures were homogenized by vortexing the plates. Both the success of the drug susceptibility assay and the appropriate volume of haemolysed culture to use for each assay were determined for each clinical isolate during a preliminary HRP2 ELISA. Both the pre-test and subsequent ELISAs were performed using a commercial kit (Malaria Ag Celisa, ref KM2159, Cellabs PTY LTD, Brookvale, Australia) according to the manufacturer's recommendations. The optical density (OD) of each sample was measured with a spectrophotometer (Multiskan EX, Thermo Scientific, Vantaa, Finland).

The concentration at which the drugs were able to inhibit $50 \%$ of parasite growth $\left(\mathrm{IC}_{50}\right)$ was calculated with the inhibitory sigmoid $E_{\max }$ model, with estimation of the $\mathrm{IC}_{50}$ through non-linear regression using a standard function of the R software (ICEstimator version 1.2) [9]. $\mathrm{IC}_{50}$ values were validated only if the $\mathrm{OD}$ ratio $(\mathrm{OD}$ at concentration $0 / \mathrm{OD}$ at concentration $\max$ ) was greater than 1.6 and the confidence interval ratio (upper 95\% 
confidence interval of the $\mathrm{IC}_{50}$ estimation/lower $95 \%$ confidence interval of the $\mathrm{IC}_{50}$ estimation) was less than $2.0[9]$.

\section{Data and statistical analysis}

$\mathrm{IC}_{50}$ values were analysed after logarithmic transformation and expressed as the geometric mean of the $\mathrm{IC}_{50}$ and a confidence interval of 95\% (CI95\%).

Using the Genbag conditions, the cut-off values for in vitro resistance, or reduced susceptibility, were 77 $\mathrm{nM}, 61 \mathrm{nM}, 115 \mathrm{nM}, 12 \mathrm{nM}, 12 \mathrm{nM}, 611 \mathrm{nM}$, and 30 $\mathrm{nM}$ for CQ, MDAQ, LMF, DHA, AS, QN, and MQ, respectively [10].

\section{Results}

Of the 24 patients recruited at the Hôpital Principal de Dakar, 19 were tested ex vivo, and 18 isolates were successfully cultured. The average parameter estimates for the ten anti-malarial drugs used against the $P$. falciparum isolates are given in Table 1 . The prevalence of $P$. falciparum isolates with decreased susceptibility to MQ in vitro reached $55.6 \%$. Fifty per cent of the isolates were resistant in vitro to $\mathrm{CQ}$.

\section{Discussion}

This report describes the evaluation of the ex vivo susceptibility of $P$. falciparum isolates, taken from patients in Dakar, to ten standard or potential anti-malarial drugs. The patients, recruited at the Hôpital Principal de Dakar from November 2013 to January 2014, said that they did not leave Dakar and its surrounding suburbs during the month preceding their malaria attack.

One limitation of this study was the low number of recruited patients (24) during those two months, due to the diminution of malaria prevalence in Senegal. The malaria prevalence in public health facilities decreased from $17.9 \%$ in 2007 to $2.6 \%$ in 2008 in Dakar [11]. In Dielmo, a village located at $280 \mathrm{~km}$ southeast of Dakar and approximately $15 \mathrm{~km}$ north of The Gambia border, the prevalence of malaria decreased from 87.2 to $0.3 \%$ in children and 58.3 to $0.3 \%$ from 1990 to 2012 [12].

The prevalence of isolates with reduced susceptibility to MQ remained high (55.6\%) in Dakar, but was relatively stable compared with the previous year (55 to 62\%) $[3,10]$. The level of in vitro MQ resistance increased since previous studies conducted in Dakar. In Dakar, the per cent of isolates with decreased susceptibility was $17 \%$ in 2001 [13] and 13\% in 2002 [7]. MQ prophylaxis failure has been previously described in Senegal [14], and MQ is one of the three anti-malarial drugs recommended for travellers as an anti-malarial prophylaxis in Senegal. Clinical trials are in progress to evaluate the efficacy of $\mathrm{MQ}$ for intermittent preventive treatment of infants and pregnant women, whereas MQ is still used for the treatment of uncomplicated malaria in infants in Dakar. Nevertheless, MQ has been employed relatively infrequently in Africa compared to Asia. The combination of artesunate-mefloquine, which is administered to patients in Asia, is not yet used in Senegal. However, scientific data are not available for $\mathrm{MQ}$ monotherapy, and very little data are available on the in vitro decreased susceptibility to MQ and its clinical implications in Africa. It is important to monitor the evolution of $P$. falciparum susceptibility to $\mathrm{MQ}$, to archive suspicious isolates and to correlate clinical outcomes with pharmacokinetic and phenotypic responses and with molecular markers.

As far back as 1988, in vitro P. falciparum resistance to CQ was reported in Dakar, and reports of resistance

Table 1 Ex vivo susceptibility of 18 Plasmodium falciparum isolates from Dakar to chloroquine (CQ), monodesethylamodiaquine (MDAQ), lumefantrine (LMF), dihydroartemisinin (DHA), quinine (QN), mefloquine (MQ), artesunate (AS), pyronardine (PND), piperaquine (PPQ) and Proveblue (PVB)

\begin{tabular}{|c|c|c|c|c|c|c|}
\hline \multirow[t]{2}{*}{ Drug } & \multicolumn{4}{|c|}{ Isolate $\mathrm{IC}_{50}$} & \multicolumn{2}{|c|}{ Resistance or reduced susceptibility } \\
\hline & Mean & $\mathrm{Cl} 95 \%$ & Min & $\operatorname{Max}$ & Cut-off & $\%$ \\
\hline $\mathrm{CQ}$ & $52.2 \mathrm{nM}$ & $29.1-93.9$ & 6.1 & 346.4 & $77 \mathrm{nM}$ & 50.0 \\
\hline MDAQ & $9.8 \mathrm{nM}$ & $5.5-17.4$ & 1.9 & 117.1 & $61 \mathrm{nM}$ & 5.6 \\
\hline LMF & $4.1 \mathrm{nM}$ & $2.1-8.1$ & 0.61 & 82.9 & $115 \mathrm{nM}$ & 0 \\
\hline DHA & $0.72 \mathrm{nM}$ & $0.35-1.50$ & 0.1 & 5.08 & $12 \mathrm{nM}$ & 0 \\
\hline AS & $1.35 \mathrm{nM}$ & $0.53-3.42$ & 0.12 & 5.53 & $12 \mathrm{nM}$ & 0 \\
\hline QN & $63.1 \mathrm{nM}$ & $30.9-128.7$ & 6.2 & 1430 & $611 \mathrm{nM}$ & 5.6 \\
\hline MQ & $30.1 \mathrm{nM}$ & $19.4-46.6$ & 7.1 & 63.4 & $30 \mathrm{nM}$ & 55.6 \\
\hline PND & $5.8 \mathrm{nM}$ & 3.3-10.1 & 0.4 & 19.7 & ND & ND \\
\hline PPQ & $32.2 \mathrm{nM}$ & $16.5-62.8$ & 2.5 & 168.0 & ND & ND \\
\hline PVB & $5.3 \mathrm{nM}$ & $2.8-10.1$ & 0.9 & 40.2 & ND & ND \\
\hline
\end{tabular}

Mean: geometric mean.

Cl 95\%: 95\% confidence interval.

ND: not determined. 
in other regions of the country followed shortly thereafter [15]. From 1991 to 1995, parasitological failures were observed in $21 \%$ of patients in Pikine [16]. The prevalence of in vitro $\mathrm{CQ}$ resistance then decreased in from $52 \%$ in 2002 [7] to approximately $20-25 \%$ in Dakar in 2009-2011 [3,10]. In 2013-2014, the prevalence of in vitro resistance to $\mathrm{CQ}$ in Dakar increased again to $50 \%$. A limitation of these results is the very small number of studied samples. However, this phenomenon was already described in Thies and Pikine. Parasites also became less susceptible to $\mathrm{CQ}$ from 2008 (median $\mathrm{IC}_{50}$ $=30.7 \mathrm{nM})$ to 2011 (median $\left.\mathrm{IC}_{50}=76.1 \mathrm{nM}\right)$ in Thies [4]. In Pikine, after a decrease of the prevalence of the pfcrt $76 \mathrm{~T}$ mutation, involved in $\mathrm{CQ}$ resistance, from 64-79\% before CQ withdrawal (2000 to 2003) [17-19] to $47-60 \%[20,21]$ when amodiaquine plus pyrimethaminesulphadoxine was the first-line treatment (2004-2005), this prevalence has increased slightly to $59 \%$ since ACT has been implemented (2006 to 2009) [19]. It is important to monitor the evolution of $P$. falciparum susceptibility to $C Q$.

The decrease in CQ resistance parallels the withdrawal of CQ treatment and the introduction of ACT in 2002 in Senegal. However, in 2006, CQ was still being administered to patients. In Dakar in 2006, CQ represented $5.1 \%$ of the anti-malarial drugs used in children [22] and $3.5 \%$ in 2009 [23]. The rapid dissemination of CQ resistance in Dielmo, despite strictly controlled anti-malarial drug use, argues against the re-introduction of $C Q$, at least in monotherapy, in places where the resistance allele has dropped to very low levels following the discontinuation of CQ treatment [24]. Despite the re-aquisition of CQ susceptibility, any re-introduction would likely result in a rapid re-emergence of resistant strains. Additionally, the increase of $C Q$ resistance in the hypothetical absence of CQ pressure leads to an avoidance of re-introducing CQ in Senegal. There is an urgent need to evaluate the presence and use of CQ in Dakar and to evaluate the capacity of drug pressure on CQ resistance of the different partners combined with artemisinin derivatives in ACT.

The prevalence of isolates with in vitro-reduced susceptibility to MDAQ remains low and stable in 2013 (5.6 versus $6 \%$ in 2009 and $11.8 \%$ in 2010) $[3,10]$. The resistance to amodiaquine has remained low even after the introduction of artesunate-amodiaquine in 2006 in Senegal. A study in Dakar and Mlomp from 1996 to 1998 demonstrated that monotherapy with amodiaquine remained effective for treating uncomplicated malaria in areas where CQ resistance was prevalent [25]. In 20112012, the efficacy of ASAQ was evaluated at 99.3\% [26]. However, ACT efficacy and resistance must be monitored because clinical failures, or at least extended parasite clearance times, have been described in Southeast
Asia [27-30]. In this context, it is important to implement in vitro and in vivo surveillance programmes.

No isolate exhibited reduced in vitro susceptibility to DHA or to AS. This result is consistent with previous studies that did not show any parasites resistant to AS $[7,31,32]$. However, high $\mathrm{IC}_{50}$ values can be found for artemisinin, with an $\mathrm{IC}_{50}>30 \mathrm{nM}$ in Dakar [33] and $\mathrm{AS}$ with an $\mathrm{IC}_{50}>45 \mathrm{nM}$ [13]. The median $\mathrm{IC}_{50}$ values increased from 2008 to 2011 ( 3.2 to $10.1 \mathrm{nM}$ ) with a highest $\mathrm{IC}_{50}$ value of $73.1 \mathrm{nM}$ in Thies [4]. In the present study, $\mathrm{IC}_{50}$ ranged from 0.1 to $5.08 \mathrm{nM}$ for DHA and 0.12 to $8.53 \mathrm{nM}$ for AS. However, the standard in vitro test was not adapted to follow resistance to artemisinin derivatives. The clinical resistance to artemisinin correlated with in vitro resistance, manifested by an increase in the ring-stage survival rate after contact with artemisinin (ring survival test) [34,35]. In addition, mutations in the P. falciparum K13 gene (PF3D7_1343700) that encodes the kelch propeller domain were associated with in vitro resistance to artemisinin and with delayed clearance after artemisinin treatment in southern Asia $[30,36,37]$. It will be a priority to introduce this new in vitro test in Senegal.

The other ACT first-line treatment for uncomplicated P. falciparum malaria in Senegal is the combination of artemether-lumefantrine. No isolate presented reduced susceptibility to LMF, and this prevalence was remains under 3\% in Dakar since the introduction of ACT $[3,10]$. In 2011-2012, the efficacy of artemether-lumefantrine was evaluated at $100 \%$ in Senegal [26].

A new ACT second-line treatment for uncomplicated P. falciparum malaria in Senegal is the combination of dihydroartemisinin-piperaquine (DP). DP (Artekin', Duo-Cotecxin $^{\circ}$, Eurartesim ${ }^{\circ}$ ) is administered as single daily dose for three days. It has been demonstrated to be well tolerated and highly effective for the treatment of uncomplicated P. falciparum malaria in Africa [38-40]. In 2011-2012, the efficacy of DP was evaluated at 100\% in Senegal [26]. The PPQ $\mathrm{IC}_{50}$ values (geometric mean $\mathrm{IC}_{50}=32.2 \mathrm{nM}$ ) observed in Dakar in 2013 were slightly lower than those found in other ex vivo studies in Africa (geometric mean $\mathrm{IC}_{50}=81.3 \mathrm{nM}$ and $66.8 \mathrm{nM}$ ) $[41,42]$.

The pyronaridine-artesunate combination (Pyramax ${ }^{\circ}$ ) is one of the most recent ACT combinations and is currently under development by the not-for-profit organisation Medicines for Malaria Venture (Geneva, Switzerland) and the pharmaceutical company Shin Poong Pharmaceuticals (Seoul, Republic of Korea) for the treatment of uncomplicated $P$. falciparum malaria and for the blood stages of Plasmodium vivax malaria. The efficacy of PND-artesunate was not inferior to that of artemether-lumefantrine in the treatment of uncomplicated P. falciparum malaria in Africa [43]. The PND $\mathrm{IC}_{50}$ values (geometric mean $\mathrm{IC}_{50}=5.8 \mathrm{nM}$ ) observed in Dakar 
in 2013 were comparable to those obtained in Dielmo in 1996 and 1997 (3.8 $\mathrm{nM}$ and $4.52 \mathrm{nM}$ ) [44,45].

In 2013, 7\% of isolates showed low reduced susceptibility to QN, which is in accordance with previous studies in Dakar $[3,7,10,13]$. Even in areas where QN efficacy remains good, such as sub-Saharan Africa, the susceptibility of individual P. falciparum isolates to QN has varied widely. The $\mathrm{IC}_{50} \mathrm{~S}$ for isolates collected in Dakar were 6 to $1,291 \mathrm{nM}$ in 2009 [10] and 5 to $1,195 \mathrm{nM}$ in 2010 [3]. The wide range in QN susceptibility and recent evidence for QN treatment failure observed across Africa $[46,47]$ or in Senegal in a patient who spent two months in Dielmo in 2007 [48] suggest that the evolution of parasites with reduced susceptibility may contribute to QN decreased efficacy. However, the 24 patients in this study were successfully treated with $\mathrm{QN}$.

Proveblue (PVB), which is a methylene blue preparation that complies with the European Pharmacopoeia and contains limited organic impurities and heavy metals of recognized toxicity, has previously been demonstrated to possess in vitro anti-malarial activity against 23 P. falciparum strains that were resistant to various anti-malarial drugs [49]. PVB exhibited noticeable synergistic effects in combination with MQ and QN and high synergistic effects associated with DHA [50]. Treatment with 1 to $10 \mathrm{mg} / \mathrm{kg}$ of weight of PVB for five days significantly reduced or prevented cerebral malaria in mice [51-53]. The $\mathrm{IC}_{50}$ for PVB ranged from $0.88 \mathrm{nM}$ to 40.2 $\mathrm{nM}$ with a mean of $5.3 \mathrm{nM}$. These data show that PVB is active in vitro, in line with previous studies with methylene blue with organic as well as inorganic impurities in parasites from Nigeria, Kenya and Thailande [54-56]. Another advantage of the use of PVB is that methylene blue has gametocytocidal properties and can reduce the transmission of $P$. falciparum $[57,58]$.

Limitations must be taken into account such as the very small number of samples which are not representative of susceptibility in Senegal but only from a facility in Dakar, the Hôpital Principal de Dakar, which certainly selects most severe malaria than in neighborhood clinics.

The introduction of ACT in 2002 in Senegal did not induce a decrease in P. falciparum susceptibility to individual drug components, such as DHA, AS, MDAQ, and LMF. The prevalence of $P$. falciparum isolates with reduced drug susceptibility to MQ remains high and stable in Dakar. Since 2004, the prevalence of CQ resistance has decreased, but then rebounded in 2013 in Dakar. PND, PPQ and PVB showed high in vitro activity against P. falciparum parasites from Dakar. Maximizing the efficacy and longevity of ACT as a tool to control malaria will critically depend on pursuing intensive research into identifying in vitro markers as well as implementing ex vivo and in vivo surveillance programmes.
Competing interests

The authors declare that they have no competing interests.

\section{Authors' contributions}

$B F, Y D$ and BP carried out the in vitro testing of drug susceptibility. CC, MF, $\mathrm{PD}$, and $\mathrm{BD}$ supervised, carried out and coordinated the field collection of isolates from patients. BW and BP conceived and coordinated the study. BP analysed the data. BF and BP drafted the manuscript. All authors read and approved the final manuscript.

\section{Acknowledgements}

The authors thank the patients and the staff of the Hôpital Principal de Dakar. The authors thank Ndeye Fatou Diop and Maurice Gomis from the Hôpital Principal de Dakar for technical support.

This study was supported by the Schéma directeur Paludisme, Etat Major des Armées Françaises (grant LR 607a) and by the Ministère des Affaires Etrangères.

\section{Author details}

'Laboratoire d'étude de la chimiosensibilité du paludisme, Fédération des laboratoires, Hôpital Principal de Dakar, Dakar, Sénégal. ²Service des Urgences, Hôpital Principal de Dakar, Dakar, Sénégal. ${ }^{3}$ Service de Réanimation Médicale, Hôpital Principal de Dakar, Dakar, Sénégal. ${ }^{4}$ Service de Pédiatrie, Hôpital Principal de Dakar, Dakar, Sénégal. ${ }^{5}$ Maternité Hôpital Principal de Dakar, Dakar, Sénégal. ${ }^{6}$ Chefferie, Hôpital Principal de Dakar, Dakar, Sénégal. ${ }^{7}$ Unité de Parasitologie et d'Entomologie, Département des Maladies Infectieuses, Institut de Recherche Biomédicale des Armées, Brétigny sur Orge, France. ${ }^{8}$ Aix Marseille Université, Unité de Recherche sur les Maladies Infectieuses et Tropicales Emergentes, UM 63, CNRS 7278, IRD 198, Inserm 1095, Marseille, France. ${ }^{9}$ Centre National de Référence du Paludisme, Marseille, France.

Received: 9 October 2014 Accepted: 27 January 2015

Published online: 06 February 2015

\section{References}

1. Ndiaye JLA, Faye B, Gueye A, Tine R, Ndiaye D, Tchania C, et al. Repeated treatment of recurrent uncomplicated Plasmodium falciparum malaria in Senegal with fixed-dose artesunate plus amodiaquine versus fixed-dose artemether plus lumefantrine: a randomized, open-label trial. Malar J. 2011;10:237

2. Thiam S, Thior M, Faye B, Diouf ML, Diouf MB, Diallo I, et al. Major reduction in anti-malarial drug consumption in Senegal after nation-wide introduction of malaria rapid diagnostic tests. PLoS One. 2011;6:18419.

3. Fall B, Pascual A, Sarr FD, Wurtz N, Richard V, Baret E, et al. Plasmodium falciparum susceptibility to anti-malarial drugs in Dakar, Senegal: an ex vivo and drug resistance molecular markers study. Malar J. 2013;12:107.

4. Van Tyne D, Dieye B, Valim C, Daniels RF, Diogoye Sène P, Lukens AK, et al. Changes in drug sensitivity and anti-malarial drug resistance mutations over time among Plasmodium falciparum parasites in Senegal. Malar J. 2013;12:441.

5. Lambros C, Vanderberg JP. Synchronization of Plasmodium falciparum erythrocytic stages in culture. J Parasitol. 1979;65:418-20.

6. Bogreau H, Renaud F, Bouchiba H, Durand P, Assi SB, Henry MC, et al. Genetic diversity and structure of African Plasmodium falciparum populations in urban and rural areas. Am J Trop Med Hyg. 2006;74:953-9.

7. Henry M, Diallo I, Bordes J, Ka S, Pradines B, Diatta B, et al. Urban malaria in Dakar, Senegal: chemosusceptibility and genetic diversity of Plasmodium falciparum isolates. Am J Trop Med Hyg. 2006;75:146-51.

8. Pascual A, Basco LK, Baret E, Amalvict R, Travers D, Rogier C, et al. Use of the atmospheric generators for capnophilic bacteria Genbag $\mathrm{CO}_{2}{ }^{\oplus}$ for the evaluation of in vitro Plasmodium falciparum susceptibility to standard antimalarial drugs. Malar J. 2011;10:8.

9. Le Nagard $\mathrm{H}$, Vincent $C$, Mentré $F$, Le Bras J. Online analysis of in vitro resistance to antimalarial drugs through nonlinear regression. Comput Methods Programs Biomed. 2011;104:10-8.

10. Fall B, Diawara S, Sow K, Baret E, Diatta B, Fall KB, et al. Ex vivo susceptibility of Plasmodium isolates from Dakar, Senegal, to seven standard anti-malarial drugs. Malar J. 2011;10:310. 
11. Drame PM, Machault V, Diallo A, Cornélie S, Poinsignon A, Lalou R, et al. IgG responses to the gSG6-P1 salivary peptide for evaluating human exposure to Anopheles bites in urban areas of Dakar. Senegal Malar J. 2012;11:72.

12. Trape JF, Tall A, Sokhna C, Badara Ly A, Diagne N, Ndiath O, et al. The rise and fall of malaria in a west African rural community, Dielmo, Senegal, from 1990 to 2012: a 22 year longitudinal study. Lancet Infect Dis. 2014;14:476-88.

13. Jambou $R_{\text {, Legrand }}$, Niang M, Khim N, Lim P, Volney B, et al. Resistance of Plasmodium falciparum field isolates to in vitro artemether and point mutations of the SERCA-type PfATPase6. Lancet. 2005;366:1960-3.

14. Gari-Toussaint M, Pradines B, Mondain V, Keundjian A, Dellamonica P, Le Fichoux Y. Sénégal et paludisme. Echec prophylactique vrai de la méfloquine. Presse Med. 2002;31:1136.

15. Hatin I, Trape JF, Legros F, Bauchet J, Le Bras J. Susceptibility of Plasmodium falciparum strains to mefloquine in an urban area in Senegal. Bull World Health Organ. 1992;70:363-7.

16. Sokhna C, Molez JF, Ndiaye P, Sane B, Trape JF. Tests in vivo de chimiosensibilite de Plasmodium falciparum à la chloroquine au Sénégal: évolution de la résistance et estimation de l'efficacité thérapeutique. Bull Soc Pathol Exot. 1997;90:83-9.

17. Thomas SM, Ndir O, Dieng T, Mboup S, Wypij D, Maguire JH, et al. In vitro chloroquine susceptibility and PCR analysis of pfcrt and pfmdr1 polymorphisms in Plasmodium falciparum isolates from Senegal. Am J Trop Med Hyg. 2002;66:474-80.

18. Sarr O, Myrick A, Daily J, Diop BM, Dieng T, Ndir O, et al. In vivo and in vitro analysis of chloroquine resistance in Plasmodium falciparum isolates from Senegal. Parasitol Res. 2005;97:136-40.

19. Ly O, Gueye PE, Deme AB, Dieng T, Badiane AS, Ahouidi AD, et al. Evolution of the pfcrt T76 and pfmdr 1 Y 86 markers and chloroquine susceptibility 8 years after cessation of chloroquine use in Pikine, Senegal. Parasitol Res. 2012;111:1541-6.

20. Sarr O, Ahouidi AD, Ly O, Daily JP, Ndiaye D, Ndir O, et al. Mutations in PFCRT K76T do no correlate with sulfadoxine-pyrimethamine-amodiaquine failure in Pikine. Parasitol Res. 2008;103:765-9.

21. Gharbi M, Flegg JA, Hubert V, Kendjo E, Metcalf JE, Bertaux L, et al Longitudinal study assessing the return of chloroquine susceptibility of Plasmodium falciparum in isolates from travellers returning from West and Central Africa, 2000-2011. Malar J. 2013;12:35.

22. Ministère de la Santé et de la Prévention Médicale. Enquête nationale sur le paludisme au Sénégal 2006. 2007. http://www.measuredhs.com/pubs/pdf/ MIS1/MIS1.pdf.

23. Ministère de la Santé et de la Prévention Médicale. Enquête nationale sur le paludisme au Sénégal 2008-2009. 2009. http://www.measuredhs.com/pubs/ pdf/MIS5/MIS5.pdf [revised30Sep2009].

24. Noranate N, Durand R, Tall A, Marrama L, Spiegel A, Sokhna C, et al. Rapid dissemination of Plasmodium falciparum drug resistance despite strictly controlled antimalarial use. Plos One. 2007;1:139.

25. Brasseur P, Guiguemde R, Diallo S, Guiyedi V, Kombila M, Ringwald P, et al. Amodiaquine remains effective for treating ucomplicated malaria in West and Central Africa. Trans R Soc Trop Med Hyg. 1999;93:645-50.

26. Ndiaye JL, Randrianarivelojosia M, Sagara I, Brasseur P, Ndiaye I, Faye B, et al. Randomized, multicentre assessment of the efficacy and safety of ASAQ - a fixed dose artesunate-amodiaquine combination therapy in the treatment of uncomplicated Plasmodium falciparum malaria. Malar J. 2009;8:125.

27. Dondorp AM, Nosten F, Yi P, Das D, Phyo AP, Tarning J, et al. Artemisinin resistance in Plasmodium falciparum malaria. N Engl J Med. 2009;361:455-67.

28. Noedl H, Se Y, Schaecher K, Smith BL, Socheat D, Fukuda MM. Evidence of artemisinin-resistant malaria in western Cambodia. N Engl J Med. 2008;359:2619-20

29. Phyo AP, Nkhoma S, Stepniewska K, Ashley EA, Nair S, McGready R, et al. Emergence of artemisinin-resistant malaria on the western border of Thailand: a longitudinal study. Lancet. 2012;379:1960-6.

30. Ashley EA, Dhorda M, Fairhurst RM, Amaratunga C, Lim P, Suon S, et al. Spread of artemisinin resistance in Plasmodium falciparum malaria. N Eng $J$ Med. 2014;371:411-23.

31. Pradines B, Tall A, Rogier C, Spiegel A, Mosnier J, Marrama $L$, et al. In vitro activities of ferrochloroquine against 55 Senegalese isolates of Plasmodium falciparum in comparison with those of standard antimalarial drugs. Trop Med Int Health. 2002;7:265-70.

32. Pradines B, Mabika Mamfoumbi M, Tall A, Sokhna C, Koeck JL, Fusai T, et al. In vitro activity of tafenoquine against the asexual blood stages of
Plasmodium falciparum isolates from Gabon, Senegal, and Djibouti. Antimicrob Agents Chemother. 2006;50:3225-6.

33. Ndiaye D, Patel V, Demas A, LeRoux M, Ndir O, Mboup S, et al. An nonradioactive DAPI-based high-throughput in vitro assay to assess Plasmodium falciparum responsiveness to antimalarials - Increased sensitivity of $P$. falciparum to chloroquine in Senegal. Am J Trop Med Hyg. 2010;82:228-30.

34. Witkowski B, Amaratunga C, Khim N, Sreng S, Chim P, Kim S, et al. Novel phenotypic assays for the detection of artemisinin-resistant Plasmodium falciparum malaria in Cambodia: in-vitro and ex-vivo drug-response studies. Lancet Infect Dis. 2013;13:1043-9.

35. Witkowski B, Khim N, Chim P, Kim S, Ke S, Kloeung N, et al. Reduced artemisinin susceptibility of Plasmodium falciparum ring stages in Western Cambodia. Antimicrob Agents Chemother. 2013;57:914-23.

36. Ariey F, Witkowsky B, Amaratunga C, Beghain J, Langlois AC, Khim N, et al A molecular marker of artemisinin-resistant Plasmodium falciparum. Nature. 2014;505:50-5.

37. Amaratunga C, Witkowski B, Khim N, Menard D, Fairhurst RM. Artemisinin resistance in Plasmodium falciparum. Lancet Infect Dis. 2014;14:449-50.

38. Yavo W, Faye B, Kuete T, Djohan V, Oga SA, Kassi RR, et al. Multicentric assessment of the efficacy and tolerability of dihydroartemisinin-piperaquine compared to artemether-lumefantrine in the treatment of uncomplicated Plasmodium falciparum malaria in sub-Saharan Africa. Malar J. 2011;10:198.

39. Yeka A, Tibenderana J, Achan J, D'Alessandro U, Talisuna AO. Efficacy of quinine, artemether-lumefantrine and dihydroartemisinin-piperaquine as rescue treatment for uncomplicated malaria in Ugandan children. PLoS One. 2013;8:53772.

40. Agarwal A, McMorrow M, Onyango P, Otieno K, Odero C, Williamson J, et al. A randomized trial of artemether-lumefantrine and dihydroartemisininpiperaquine in the treatment of uncomplicated malaria among children in western Kenya. Malar J. 2013;12:254

41. Pascual A, Madamet M, Bertaux L, Amalvict R, Benoit N, Travers D, et al. In vitro piperaquine susceptibility is not associated with the Plasmodium falciparum chloroquine resistance transporter gene. Malar J. 2013;12:431.

42. Pascual A, Parola P, Benoit-Vical F, Simon F, Malvy D, Picot S, et al. Ex vivo activity of the ACT new components pyronaridine and piperaquine in comparison with conventional ACT drugs against isolates of Plasmodium falciparum. Malar J. 2012;11:45.

43. Brandicourt $O$, Druilhe $P$, Diouf F, Brasseur P, Turk P, Danis M. Decreased sensitivity to chloroquine and quinine of some Plasmodium falciparum strains from Senegal in september 1984. Am J Trop Med Hyg. 1986;35:717-21.

44. Pradines B, Tall A, Parzy D, Spiegel A, Fusai T, Hienne R, et al. In vitro activity of pyronaridine and amodiaquine against African isolates (Senegal) of Plasmodium falciparum in comparison with standard antimalarial agents. J Antimicrob Chemother. 1998:42:333-9.

45. Pradines B, Tall A, Ramiandrasoa F, Spiegel A, Sokhna C, Fusai T, et al. In vitro activity of iron-binding compounds against Senegalese isolates of Plasmodium falciparum. J Antimicrob Chemother. 2006;57:1093-9.

46. Jelinek T, Schelbert P, Loscher T, Eichenlaub D. Quinine resistant falciparum malaria acquired in east Africa. Trop Med Parasitol. 1995;46:38-40.

47. Palmieri F, Petrosillo N, Paglia MG, Conte A, Goletti D, Pucillo LP, et al. Genetic confirmation of quinine-resistant Plasmodium falciparum malaria followed by postmalaria neurological syndrome in a traveler from Mozambique. J Clin Microbiol. 2004;42:5424-6.

48. Pradines B, Pistone T, Ezzedine K, Briolant S, Bertaux L, Receveur MC, et al. Quinine-resistant malaria in traveler returning from Senegal, 2007. Emerg Infect Dis. 2010;16:546-8.

49. Pascual A, Henry M, Briolant S, Charras S, Baret E, Amalvict R, et al. In vitro activity of Proveblue (methylene blue) on Plasmodium falciparum strains resistant to standard antimalarial drugs. Antimicrob Agents Chemother. 2011;55:2472-4.

50. Dormoi J, Pascual A, Briolant S, Amalvict R, Charras S, Baret E, et al. Proveblue (methylene blue) as antimalarial agent: in vitro synergy with dihydroartemisinin and atorvastatin. Antimicrob Agents Chemother. 2012;56:3467-9.

51. Dormoi J, Briolant S, Desgrouas C, Pradines B. Efficacy of Proveblue (methylene blue) in an experimental cerebral murine model. Antimicrob Agents Chemother. 2013;57:3412-4

52. Dormoi J, Briolant S, Desgrouas C, Pradines B. Impact of methylene blue and atorvastatin combination therapy on the apparition of cerebral malaria in a murine model. Malar J. 2013;12:127. 
53. Dormoi J, Pradines B. Dose responses of Proveblue methylene blue in an experimental murine cerebral malaria model. Antimicrob Agents Chemother. 2013;57:4080-1.

54. Ademowo OG, Nneji CM, Adedapo AD. In vitro antimalarial activity of methylene blue against field isolates of Plasmodium falciparum from children in Southeast Nigeria. Indian J Med Res. 2007:126:45-9.

55. Okombo J, Kiara SM, Mwai L, Pole L, Ohuma E, Ochola LI, et al. Baseline of the activities of the antimalarials pyronaridine and methylene blue against Plasmodium falciparum isolates from Kenya. Antimicrob Agents Chemother. 2012;56:1105-7.

56. Suwanarusk R, Russel B, Ong A, Sriprawat K, Chu CS, Phyo AP, et al. Methylene blue inhibits the asexual development of vivax malaria parasites from a region of increasing chloroquine resistance. J Antimicrob Chemother. 2014. in press.

57. Adjalley SH, Jonhston GL, Li T, Eastman RT, Ekland EH, Eappen AG, et al. Quantitative assessment of Plasmodium falciparum sexual development revels potent transmission-blocking activity by methylene blue. Proc Nat Acad Sci U S A. 2011;108:1214-23.

58. Coulibaly B, Zoungrana A, Mockenhaupt FP, Schirmer RH, Klose C,

Mansmann $U$, et al. Strong gametocytocidal effect of methylene blue-based combination therapy against falciparum malaria: a randomized control trial. PLoS One. 2009;4:5318.

\section{Submit your next manuscript to BioMed Central and take full advantage of:}

- Convenient online submission

- Thorough peer review

- No space constraints or color figure charges

- Immediate publication on acceptance

- Inclusion in PubMed, CAS, Scopus and Google Scholar

- Research which is freely available for redistribution 